\title{
Los significados de la paternidad desde la construcción de lo masculino: el caso de la Pincoya ${ }^{1-2}$
}

\author{
Claudia Jara Silva ${ }^{3}$
}

\begin{abstract}
Este artículo presenta los resultados de una investigación cuyo objetivo fue analizar los significados que asignan a la paternidad varones jóvenes habitantes de la población La Pincoya, comuna de Huechuraba, Región Metropolitana de Santiago, Chile, como factor constitutivo de su masculinidad. La metodología empleada fue de tipo cualitativa y buscó mostrar las percepciones de varones que viven en sectores empobrecidos, desde su posición de padres. El propósito fue deconstruir formas de conocimiento históricas tradicionales, para comprender desde la reflexión crítica los significados que adquiere la paternidad para estos jóvenes, ello mediado por la perspectiva del conocimiento situado, como eje ordenador de las investigaciones feministas.
\end{abstract}

Palabras clave: Identidades de género, construcción de masculinidad, sectores empobrecidos, significados de paternidad.

\section{Os significados da paternidade desde a construção do masculino: $O$ caso de La Pincoya}

\author{
RESUMO
}

Este artigo apresenta os resultados de uma pesquisa cujo objetivo foi analisar os significados que assignam à paternidade, homens jovens habitantes da povoação La Pincoya, comuna de Huechuraba, Região Metropolitana de Santiago, Chile, como fator constitutivo da sua masculinidade. A metodologia empregada foi de tipo qualitativo e procurou mostrar as percepções de homens que moram em sectores empobrecidos, desde sua posição de pais. O propósito foi de desconstruir formas de conhecimento históricas-tradicionais, para compreender desde a reflexão crítica os significados que adquire a paternidade para estes jovens, aquilo, mediado

1 Artículo recibido el 27/22/2017. Articulo aprobado el 15/03/2018

2 Proyecto de investigación para optar al grado de Magíster en Estudios de Género y Cultura, mención Ciencias Sociales, Universidad de Chile

3 Chilena, Trabajadora Social, Consultora: "Enfócate miradas situadas para la intervención SpA". E-mal: cjarasilva@gmail.com. 
Los significados de la paternidad desde la construcción de lo masculino: el caso de la Pincoya /Jara

pela perspectiva do conhecimento situado, como eixo ordenador das pesquisas feministas.

Palavras-chave: Identidades de gênero, construção de masculinidade, sectores empobrecidos, significados de paternidade.

\section{The meanings of fatherhood from the construction of the masculine: The case of La Pincoya}

ABSTRACT

The article presents the results of a research project to qualify for the Master's degree in Gender and Culture Studies, with a Major in Social Sciences, from the University of Chile. The article's objective was to analyze the meanings of paternity as a constitutive factor of masculinity in young male inhabitants of La Pincoya slum. In this study we used a qualitative methodology in order to show the vision of men living in impoverished sectors that are often not heard in their social position. The aim was to deconstruct historicaltraditional forms of knowledge in order to understand from a critical reflection, the meaning that fatherhood acquires for these young people. All this is mediated from the perspective of knowledge located as the central axis of feminist researches.

Keywords: Gender identities, masculinity construction, impoverished sectors, meaning of fatherhood.

\section{Antecedentes generales}

Los elementos del contexto actual se caracterizan por una creciente agudización de la desigualdad, fruto de una brecha social cada vez más amplia entre los sectores ricos y empobrecidos de la población. Esta distancia tiende a medirse en términos de ingresos, siendo la más común, pero no la única, la económica (Barozet, 2012). También puede medirse de otras formas, como acceso a la salud, a la educación, entre otras.

Desde la economía, la distribución del ingreso suele reflejarse mediante el índice Gini que, de acuerdo con el informe de la encuesta CASEN 2015, alcanzó un valor de 0.495, lo que ubica a Chile entre los países con peor distribución de la riqueza a nivel mundial. Su patrón de desigualdad se caracteriza por la "concentración en la elite"; bajo este nivel, los ingresos muestran un nivel de desigualdad considerablemente menor (Torche, 2005). 
Esta desigualdad está inscrita históricamente en la estructura económica y social del país, son estas mismas élites las que han concentrado, desde los tiempos de la Colonia, el poder económico, el poder político y la influencia social, "la desigualdad de los ingresos en América Latina tiene su base y su origen en una etapa muy lejana de la historia y se relaciona con las características propias que asumió el proceso de colonización en el continente" (Ottone y Vergara; 2007, p. 63).

Existen causas estructurales que explican los altos niveles de inequidad, que constituye un sistema de perpetuación y agudización en el tiempo de la brecha de ingresos entre los distintos grupos sociales. Estas radican principalmente en las diferencias en el acceso a activos, entendidos como la educación, el conocimiento, empleos de calidad y, en medida diversa, el acceso a otros activos, como tierra, capital y financiamiento. Estas son las cadenas que reproducen la inequidad, son altamente transmisibles de una generación a la siguiente y, por ello, perpetúan la mala distribución del ingreso pese a los esfuerzos del Estado por intervenir para apoyar a los grupos más pobres (Ottone y Vergara, 2007).

La modernidad no ha significado la generación de mayores cambios en este sentido. El acceso a la educación superior sigue siendo un obstáculo en Chile, los estudiantes y sus familias deben endeudarse por largos años para lograr alcanzar un título profesional. A ello se suma que los que provienen de sectores empobrecidos no siempre logran incorporarse a la educación superior y, si ingresan, lo hacen a entidades como institutos o universidades privadas, donde la calidad de la educación no es siempre la mejor. Al respecto, la OCDE (2009), en su informe acerca de la educación superior en Chile, señala que los alumnos de escuelas municipalizadas y familias más pobres tienen mucho menos posibilidades de aprobar la PSU que los de colegios privados y familias ricas. Si la aprueban, es menos probable que logren los puntajes más altos que les permitirían tener acceso a los programas de apoyo financiero y a las mejores universidades. 
La implementación durante la dictadura militar del sistema económico e ideológico neoliberal, trajo como consecuencia la privatización de servicios que durante años habían sido públicos, como la salud, educación y previsión, lo que sirvió a los intereses de las grandes empresas, así como a la concentración de recursos económicos, contribuyendo al aumento de las desigualdades. Durante años, el modelo acarreo mayor pobreza e inequidad a Chile (Barozet, Espinoza y Medel, 2011).

Los gobiernos democráticos que ejercieron el poder después de los noventa no alteraron profundamente el sistema económico imperante. En las dos décadas siguientes, Chile experimentó una notable expansión económica, con un crecimiento medio de alrededor del 5\% anual; junto con ello, era el cuarto país más desigual en la región $(\mathrm{Gini}=0.51)$. No obstante, durante estos primeros veinte años, la pobreza en Chile se redujo desde el $40 \%$ hasta bajo el $20 \%$, constituyéndose en el caso más exitoso en la región latinoamericana. Por otro lado, la superación de la pobreza no estuvo asociada a una modificación de la desigualdad del ingreso, que se mantenía prácticamente a un mismo nivel (Barozet, Espinoza y Medel, 2011).

El sistema económico neoliberal favoreció la concentración de la riqueza históricamente existente en el país, acentuando la acumulación progresiva y expedita por parte de grupos minoritarios. Así lo demuestra un estudio realizado por López, Figueroa y Gutiérrez (2013), que señala que las estimaciones que incluían los antecedentes de la encuesta CASEN son subestimadas si se consideran los datos entregados por Servicio Impuestos Internos. En su investigación concluyen que la riqueza en Chile se concentra en grupos minoritarios de elite, "la participación en el ingreso personal total es extraordinariamente alta, llegando a más de 30\% para el $1 \%$ más rico, $17 \%$ para el $0,1 \%$ más rico y más de $10 \%$ para el 0,01\% más rico en promedio durante el periodo 2004-2010" (López, Figueroa y Gutiérrez 2013, p. 28). Chile presenta mayor concentración de la riqueza que gran parte del mundo capitalista, superior a EE.UU, Inglaterra y Japón. 
Esta alta concentración de la riqueza sitúa a estos grupos minoritarios en una posición de dominación, en oposición a los grupos de menores ingresos, situados en una posición de sumisión. Las fuerzas con que cada uno de ellos se mueve en este espacio global o en los espacios regionales, es siempre resultado de lo que se tiene por sobre lo que se es. Es decir, la posición social que se posea o se imponga, otorgará mayor o menor capacidad para controlar acciones y relaciones sociohistóricas (Duarte, 2000). Esta desigualdad se reproduce en el tiempo en la medida en que la mayoría de la población chilena no tiene acceso a activos como la educación, principal reivindicación de los sectores medios durante los últimos años.

Las posibilidades de acceder a empleos de mejor calidad y, en consecuencia, a mejores remuneraciones, están dadas por el nivel educacional de las personas. La educación es la variable fundamental en la determinación del salario. Una persona con educación universitaria gana tres veces más por hora que una con educación secundaria, y 5,2 veces más que una con educación primaria (Ottone y Vergara, 2007).

Un joven de un sector empobrecido, como La Pincoya, no tiene las mismas posibilidades de acceder a la educación superior que otros jóvenes provenientes de sectores sociales privilegiados. Sin embargo, la exclusión del sistema se produce previamente: la escuela producto de su propia estructura y dinámica tendiente a la normalización y homogeneización de los individuos, no logra motivar a sus estudiantes a permanecer en ella mientras transitan los diferentes niveles de enseñanza. Los estudiantes de clases sociales populares, cuya cultura difiere de la cultura escolar, deben someterse a una reeducación. Los fracasos escolares, las bajas notas y los juicios de los profesores los convencen de que son incapaces de estudiar y de que deben contentarse con un trabajo modesto de acuerdo con sus capacidades (Redondo, 2000).

Es así como se va desarrollando la exclusión de niños y jóvenes, al hacerles sentir que la educación no es para ellos, por lo tanto, 
la posibilidad de obtener condiciones de vida superiores a las que obtuvieron sus padres mediante la educación, queda eliminada. Es necesario romper la actual cadena de transmisión generacional de las oportunidades que se traduce en transmisión generacional de la pobreza, de los empleos precarios y de los bajos ingresos (Ottone y Vergara, 2007).

En nuestro país, el actual sistema capitalista neoliberal y la baja participación del Estado impone a los varones empobrecidos no solo una inserción precaria al mundo del trabajo con escasa protección laboral, asimismo limita las posibilidades de convertirse en proveedores y fundadores de familia, impidiendo el cumplimiento de ciertos mandatos sociales genéricos.

El capitalismo no es solo un modo de producción que pretende la creación y expansión del capital a través de la acumulación de plusvalía. El capitalismo hereda una especial forma de entender lo masculino y lo femenino. La organización de lo social implica el desarrollo del trabajo y de la familia, por tanto las necesidades de procreación, sexualidad o alimentación son satisfechas de una forma particular en cada cultura (Rubin, 1996).

Existen factores estructurales que intervienen en la configuración de lo femenino y masculino, siendo los sistemas de producción claves en este proceso. Las desigualdades sociales que genera el sistema económico capitalista neoliberal en nuestro país, sumadas al escaso desarrollo del Estado hoy, intervienen en las configuraciones locales y coyunturales de las construcciones genéricas, es decir, el mercado o sistema de producción y su relación con el Estado dispone las formas de ser y relacionarse entre hombres y mujeres, adquiriendo ribetes y tensiones diferentes de acuerdo a otros elementos, como la posición que ocupen los sujetos en la estructura social (Salazar, 2012).

Así, un varón de un sector empobrecido construirá su masculinidad de acuerdo a las posibilidades que ofrezca el sistema social. El paso de un Estado de Bienestar a uno subsidiario, sumado a las crecientes necesidades de consumo que impone el sistema neoli- 
beral bajo un contexto de desprotección laboral y social, marcará el posterior desarrollo de las paternidades.

Toda sociedad tiene alguna forma de actividad económica organizada, así también toda sociedad tiene un sistema sexo/género que define roles diferenciados para hombres y mujeres, y formas específicas de relaciones entre ambos, es decir, un modo particular de reproducción de relaciones sociales y sexuales. Por consiguiente, el patriarcado -sistema sexo/género y forma de organización de la sociedad que otorga al hombre, convertido en padre y en patriarca, la autoridad máxima sobre la familia- proyecta esta posición de superioridad del varón al resto de la sociedad, otorgando a las mujeres una posición de inferioridad y de opresión, convirtiéndose en un elemento más en la reproducción del capitalismo (Rubin, 1996).

La opresión de las mujeres no es una cuestión biológica, sino una propiedad de los sistemas sociales que configura las sociedades en distintas épocas. La división sexual del trabajo divide los sexos en dos, exacerba las diferencias biológicas en contra de la igualdad de hombres y mujeres, creando el género a partir de estas diferencias biológicas e imponiendo una forma específica de relación sexo afectiva entre ambos: la heterosexualidad (Rubin, 1996).

La división sexual del trabajo y las relaciones de subordinación que conlleva se materializa en el espacio familiar con la llegada de los hijos/as. Son las mujeres convertidas en esposas, domésticas, madres, quienes se encargan principalmente de las tareas relacionadas con la crianza y cuidado de los hijos. Incluso si la mujer trabaja remuneradamente fuera del hogar, queda sujeta a estas exigencias como principal responsable, bajo un tipo específico de relación. Como señala Rubin (1986), siguiendo a Marx, las mujeres son mujeres, pero en ciertas relaciones se convierten en domésticas y subordinadas.

Por el contrario, los varones-padres se encargan principalmente de sustentar económicamente al grupo familiar, cumpliendo con los mandatos de género que los sitúa en ese rol. Aunque ambos 
trabajen siguen siendo los principales proveedores, generalmente estos perciben mejores remuneraciones que las mujeres ${ }^{4}$. Trabajan largas jornadas para cumplir con este propósito ${ }^{5}$ para participar del mercado a través del consumo.

La identidad femenina tradicional coloca a la maternidad como el eje alrededor del cual se articula la femineidad, ser madres confiere a las mujeres el estatus de adultas sociales y es la fuente de reconocimiento público más importante para ellas. Sin embargo, en la actualidad es el aspecto en la vida de las mujeres que más ha cambiado, compitiendo con otras fuentes de identificación y dadores de sentido, como el trabajo, la participación política, entre otros, encontrando en la actualidad otros refugios identitarios (Fuller, 2001).

Así también, en cuanto a las representaciones de la paternidad, ya no es extraño ver a padres jugando con sus hijos en la plaza, llevándolos al médico, asistiendo a reuniones de apoderados. En este sentido, algunos estudios señalan que la paternidad es el primer canal que tienen los hombres para expresar sus emociones. $\mathrm{Al}$ igual que antes la paternidad significa ser responsable económicamente de los hijos, pero, además, significa cuidado y afectividad (Figueroa y Franzoni, 2011).

Estas nuevas imágenes de la paternidad, desarrolladas durante las últimas décadas, han sido reflejadas jurídicamente a través de reformas y reformulación de leyes, surgiendo la noción de "cuidado personal compartido". Hace algunos años se aprobó en nuestro país la ley 20.680, que modifica algunos aspectos del Código Civil relacionados con el cuidado personal, en ella se otorga a los padres el derecho a optar al cuidado personal de sus hijos, basado en el principio de corresponsabilidad parental, entendida como la participación de los padres en forma activa, equitativa y permanente

4 En Chile los hombres perciben salarios mayores que las mujeres en empleos de características similares, produciendo una brecha salarial que bordea el 30\% (INE, 2015).

5 En Chile, según datos ENCLA 2011, los hombres están más involucrados que las mujeres en la realización de horas extraordinarias, alcanzando una diferencia de 4.6 p.p. 
en la crianza y cuidado de sus hijos, independiente si viven juntos o separados. Con anterioridad a esta ley, conocida popularmente como "amor de papá", el cuidado personal era ejercido en forma exclusiva por las mujeres, la legislación se fundamentaba en que las mujeres estaban más capacitadas para ejercer esta función, apelando a que era una orden de regla natural.

El lugar del padre al interior de la familia (en su dimensión institucional) y el significado de la paternidad se encuentran en un momento de redefinición. Los cambios que experimentan los padres han sido un proceso gradual, pero que no ha alcanzado la profundidad suficiente para generar o alcanzar a cubrir todos los aspectos cotidianos relacionados con la crianza y el cuidado de los hijos (Valdés, 2007). Reordenamiento que responde a un escenario de cambios y de cuestionamiento a los mandatos tradicionales patriarcales. En este sentido, los jóvenes se encuentran en una clara tensión en su proceso de construcción de identidades genéricas que, lejos de transformar las relaciones e identidades tradicionales a otras más igualitarias, han generado actualizaciones y mutaciones de la condición patriarcal (Duarte, 2011).

\section{Metodología}

Esta investigación se realizó desde el enfoque cualitativo, el cual será entendido "como las investigaciones que producen datos descriptivos: las propias palabras de las personas, habladas o escritas y la conducta observable" (Taylor y Bogdan, 1987, p. 20). En los estudios cualitativos se estudia a aquellas personas a las que la sociedad ignora, entre ellos, los pobres, por lo tanto, es una ocasión para que expongan sus puntos de vista.

La información se analizó desde la "teoría crítica", concepto amplio que denota una serie de paradigmas, incluyendo adicionalmente al neomarxismo, feminismo, materialismo, y la investigación participativa. Tienen en común la innovadora suposición de que la naturaleza de la investigación está regida por los valores, lo cual crea una diferencia epistemológica (Guba y Lincoln, 2002). El 
"para qué" conocer obliga a pensar en los valores que están latentes en la investigación; en el caso del presente estudio, existió un claro compromiso de transformación ante las situaciones de injusticia que afectan a varones, mujeres, y niño/as de La Pincoya, bajo una estructura de asimetrías sociales y sexuales.

Es importante mencionar que la construcción de conocimiento siempre se realiza desde una posición determinada, en nuestro caso como investigadora mujer, con una historia particular desde el lugar de hija, con experiencias relacionadas con niñas y niños en contextos empobrecidos, y con un interés en deconstruir formas tradicionales de analizar la realidad social que apunte a la justicia social como objetivo fundamental del Trabajo Social. Al respecto, Haraway (1991) señala que entiende al sujeto del conocimiento como a un individuo histórico particular y no como a un sujeto abstracto y valorativamente neutro. De este modo, su cuerpo, intereses, emociones y razón están constituidas por su contexto histórico concreto, y son especialmente relevantes para la epistemología. Así, el conocimiento es siempre situado.

La investigación fue abordada desde el estudio de caso que permite la aproximación a la historia personal de un individuo y a los valores y normas del contexto social (Serrano 1995).

\section{Sujetos de la investigación y estrategias de producción de la información}

Los sujetos de la investigación fueron varones, jóvenes entre 18 y 29 años, padres y habitantes de la población La Pincoya desde su nacimiento o desde su infancia. Se utilizó la técnica de entrevista en profundidad, porque es una técnica de recolección de información que nos acerca a la información tanto verbal como no verbal, la que es interpretada durante la interacción cara a cara y que condiciona el grado de profundidad alcanzado durante el desarrollo de la entrevista (Canales, 2006).

Por último, el análisis de contenido fue la técnica utilizada para la interpretación de texto, la que combina intrínsecamente la ob- 
servación y producción de datos. El propósito fundamental del análisis de contenido es realizar inferencias, entendido como la comunicación simbólica o mensajes de los datos (Andréu, 1998).

\section{Resultados}

Los resultados se organizan dando respuesta los objetivos de la investigación.

\section{Identidades genéricas en tensión: nuevos discursos en viejas costumbres}

Las actuales transformaciones sociales no logran mermar la importancia de la maternidad en la construcción de la identidad femenina; sin embargo, según sostiene Norma Fuller (2001), es uno de los aspectos en la vida las mujeres que más ha cambiado durante los últimos años, junto a ello, la construcción de la identidad femenina. La creación de los métodos anticonceptivos permitió escindir sexualidad de reproducción, dando espacio a una nueva dimensión en la vida sexual de las mujeres: el erotismo. La eficacia de los métodos permitió mayor control del número de hijos e hijas, reduciendo considerablemente la fertilidad, también permitió retardar la maternidad y, con ello, compatibilizar diversas tareas. A lo anterior se agrega que la prolongación de la esperanza de vida de las mujeres permite que el tiempo dedicado a la reproducción y a la crianza sea proporcionalmente menor que al tener una vida menos larga.

No obstante, para un número importante de ellas, la maternidad sigue siendo el principio ordenador de la identidad femenina, naturalizando la reproducción biológica y cultural como un aspecto fundamental en sus vidas. Este proceso está condicionado al contexto social donde se desarrolla la experiencia. En sectores empobrecidos existen limitadas posibilidades de reconocimiento público para las mujeres, participan menos en el mercado laboral en comparación a los segmentos de mayores ingresos. Aproximadamente un 26\% de ellas tiene un trabajo (Sernam, 2007). Convertirse en madres les 
otorgaría estatus de adultas sociales y representaría una fuente de reconocimiento público importante para ellas (Fuller, 2001).

Es así como la construcción de identidad femenina para los jóvenes padres está simbolizada en la maternidad. Continúan considerando que la reproducción y la crianza son tareas propias de las mujeres, naturalizando su lugar en este espacio: "son más de casa", "les gusta estar con los hijos". En este sentido, a pesar de las transformaciones de la maternidad y su incidencia en la construcción de la identidad femenina, no logran disociar la madre de la mujer, como si fuesen lo mismo.

Manifiestan que las mujeres son capaces de asumir distintas jornadas de trabajo con la finalidad de brindar mejores condiciones de vida a sus hijos, reactualizando al sacrificio como valor importante en la identidad femenina desde la maternidad. Si bien valoran positivamente que las mujeres se atrevan a ocupar espacios y asumir otros roles distintos a los tradicionales, los padres estimulan a sus compañeras a emprender distintos caminos como trabajar y estudiar, sin embargo, justifican que el gran esfuerzo que realizan es para mejorar las condiciones de vida de su hijo/a. No se menciona el proyecto personal como dador de sentido en estos nuevos desafíos que las mujeres emprenden.

Cuestionan las conductas sexuales de las mujeres que pudiesen estar más cercanas al placer y al erotismo, y menos orientadas a la procreación o a la sexualidad con fines exclusivamente reproductivos. Estas percepciones se distancian de las prácticas sexuales de las mujeres en la actualidad, y que, en palabras de Giddens (1995), arrastran los ecos del pasado, desde la hegemonía patriarcal.

Los padres señalan que las mujeres mantienen su presencia y dominio en el espacio doméstico, lugar que ha estado históricamente bajo su control, pero hoy, debido a los nuevos desafíos, deben compatibilizar con sus nuevos roles, multiplicando y triplicando las horas de trabajo para ellas, sin cuestionar sus propias prácticas. 
La masculinidad, en cambio, se define como "todo aquello que no es femenino"; los varones deben luchar constantemente por convencerse a sí mismos y a los demás que no son mujeres, ni homosexuales, como tampoco niños. Necesitan que su identidad sea reconocida y se construye fundamentalmente en representaciones como la fuerza y la razón. Desde su concepción, el embrión masculino lucha para no ser femenino, nacido de una mujer, mecido en un vientre; el niño macho al contrario de lo que sucede con la hembra, se va condenando a marcar diferencias durante la mayor parte de su vida (Badinter, 1993).

Es así como los jóvenes de la población La Pincoya establecen claras diferencias con las mujeres, no realizan acciones que parezcan femeninas, no exponen sus sentimientos, y reprimen sus emociones. No dan cabida a las dudas en torno a su heterosexualidad, norma masculina, "te enseñan desde chiquititos que te deben gustar las mujeres"; así, la heteronormatividad aparece como único modelo válido de relación sexo afectiva y de parentesco. Uno de los núcleos centrales en la construcción de la identidad genérica heterosexual es la rígida percepción de las personas como cuerpos sexuales duales. Así, tampoco son niños, la madurez es un paso importante que deben dar para convertirse en hombres.

La construcción de la masculinidad es un proceso en el que los hombres se someten a cierta ortopedia desde la infancia. "Ser hombre" es algo que se debe lograr, conquistar y merecer. Para hacerse "hombre" adulto los varones deben superar ciertas pruebas, como iniciarse en el trabajo, formar un hogar, proveer y tener hijos para ser aceptados como "hombres" por los otros varones (Olavarría, 2001).

Para los sujetos de la investigación principalmente significa trabajar, utilizando para ello la fuerza física. Proveer es otra prueba que deben superar los varones, en un medio donde es complejo subsistir, siendo difícil para ellos cumplir con esta expectativa. Los empleos a los cuales acceden no son bien remunerados y, al no percibir un sueldo como se espera, sienten que pierden su función 
social en relación con las mujeres, peor aún si las mujeres perciben mayor remuneración que ellos.

Algunos autores (Olavarría, 2004; Duarte, 2013) incluyen la paternidad en las pruebas de definición de la hombría. Señalan que la paternidad sería una opción que les permite legitimarse ante la mirada de los varones adultos, ser tomado en cuenta. Para los varones de sectores empobrecidos, esta paternidad implicaría una posibilidad distinta de construcción de su identidad de género, convirtiéndose en un refugio identitario.

Sin embargo, lo que señalan los autores no coincide con los discursos de los padres de la población La Pincoya, quienes no mencionan a la paternidad como prueba de masculinidad, esto podría deberse al hecho que aún hoy la paternidad es un elemento controvertido en la construcción de la identidad masculina en nuestra cultura. La representación de la paternidad en la identidad masculina es difusa, no se logra situar claramente, muy distinto a lo que ocurre en el caso de las mujeres, en el que se percibe nítidamente la maternidad en lo femenino.

La independencia, la separación del espacio materno como lugar protegido y controlado por la madre, se convierte en otra prueba que deben pasar los varones para verse como "hombres" y no "mamones", como señala uno de los entrevistados.

\section{La calle: espacio de poder y dominio masculino}

La calle es el lugar de dominio del género masculino; desde niños los varones pasan gran parte de su tiempo en este espacio. Es el lugar donde se generan relaciones de confianza con otros hombres, se viven las amistades que son parte de ser joven urbano, se refuerzan los apegos y lealtades que otorgan sentido a la existencia fuera del hogar.

Es un espacio abierto que permite a los hombres conocer y ensayar la libertad, desafiar el riesgo e interactuar con personas diferentes. Es el lugar privilegiado para los aprendizajes relacionados con sus 
identidades masculinas. En palabras de Rebolledo (1998), este espacio permite la homo socialización sostenida en el compadrazgo. No es que naturalmente los varones debían identificarse con la calle, sino más bien, ingresan por expulsión social. El contexto les impone esta salida principalmente por las dificultades que se presentan en la vida familiar, falta de espacios de intimidad, ruptura generacional, produciendo una tensión permanente entre pasar más tiempo fuera de la casa y la imposibilidad de salir definitivamente de ella, dada las condiciones socioeconómicas de los jóvenes, que les impediría esto último (Duarte, 2011).

Los jóvenes padres reconocen que el mayor tiempo transcurrido en la calle marca la transición de niño a joven. Rito de pasaje, que establece el término de la infancia y llegada de la juventud, símbolo de juventud y masculinidad para los varones. La importancia de estar en ella radica en la fortaleza y fuerza que se debe demostrar, en una lucha por la primacía en la que vence el más fuerte; en palabras de Claudio Duarte (2013), es una demostración de aguante, de su capacidad para estar en ambientes de peligro y hacerse hombre en la adversidad.

\section{Hegemonía patriarcal: nuevas actualizaciones}

El neomachismo es una nueva forma de machismo, que se rearticula de acuerdo con los principios democráticos de la época actual, que desvaloriza las relaciones jerarquizadas. A nivel de discurso, se valoran relaciones más igualitarias entre hombres y mujeres, pero opera en la práctica el peso de la costumbre (Montecino, 2010).

En el extremo social más vulnerable de la población La Pincoya, uno de los padres jóvenes no teme manifestar explícitamente que se considera machista, tal vez porque las relaciones sociales jerarquizadas tienen cierta legitimidad. No se cuestiona en las relaciones de género, como tampoco en las relaciones productivas: el patrón y el macho es quien detenta poder y así debe ser, bajo una ideología tradicional que legitima las desigualdades. 
El neo-machismo se actualiza mediante acciones de protección hacia los que siente más débiles: mujeres y niños. La supremacía como valor masculino asignado socialmente a los varones, quienes deben defender a los suyos, que "no los pasen a llevar", en un espacio que requiere acciones relacionadas con la fuerza física y la violencia para la protección de otros.

Si bien a nivel de discurso se valorizan relaciones más igualitarias entre hombres y mujeres, continúa operando en la práctica una clara división sexual del trabajo que exacerba las diferencias entre hombres y mujeres en contra de la igualdad. Siendo las relaciones de producción determinantes en la posición y condición que mujeres y hombres tienen en la vida social, la subordinación de las mujeres es parte de este proceso (Rubín, 1996).

La división sexual del trabajo no es una especialización biológica, más bien tiene otro propósito: asegurar la unión de hombres y mujeres haciendo que la mínima unidad económica viable contenga, por lo menos, a un hombre y una mujer. La división sexual del trabajo no es otra cosa que un mecanismo para constituir un estado de dependencia recíproca entre los sexos (Rubin, 1996).

Esta división sexual, en palabras de Bourdieu (2000), no solo establece papeles diferenciados para hombres y mujeres, es un principio básico de la violencia simbólica en la estructura social como parte de la dominación masculina, que hace legítima la desigualdad entre hombres y mujeres. Opera a través de diversas instituciones, reproduciendo esquemas de pensamientos que naturalizan las diferencias y la sumisión de las mujeres, de manera inadvertida.

Al respecto, Montecino (2010) señala que uno de los nudos o tensiones a resolver es la relación entre género e identidad, marcada por el poder y las jerarquías, y, en otro sentido, como multiplicidad temporo-espacial. Estos espacios, públicos y privados, en tanto espacios físico y mental, expresan sistemas jerárquicos y con una clara configuración de poder masculino de dominación. 
En este sentido, los jóvenes padres aceptan cierta flexibilización en el ejercicio de roles al interior de la organización familiar, siempre y cuando no amenace su posición de dominio al interior de este espacio. Las mujeres pueden trabajar; sin embargo, esto no significa un cambio en su posición de subordinación. Es decir, los varones aprueban el ingreso de las mujeres al mundo laboral, siempre y cuando no manden más que ellos. Se mantienen el espíritu de dominio y control en los varones como ejercicio reafirmador de su masculinidad.

\section{Organización de la vida social: la construcción de familias}

Esta división sexual del trabajo corresponde a un tipo de estructura familiar. La familia nuclear se proyectó en la teoría como la única que se adapta a las instituciones económicas con las que estaría relacionada la sociedad industrial. Este tipo de organización social familiar, con una clara diferenciación de roles entre hombres y mujeres, invisibilizó un sistema que legitimó identidades masculinas y femeninas hegemónicas y relaciones jerarquizadas entre ambas, justificando su reproducción. Esta relación, moldeada por distintos niveles de socialización, hace que cualquier otro ordenamiento parezca fuera de la norma, desvirtuado o improbable, básicamente porque fue funcional al sistema económico (León, 1995).

Permitió la conciliación trabajo-familia, que consistía justamente en que mujeres se quedaran en casa y los hombres salieran de ella para ganar el sustento. Este tipo de organización comienza a desarticularse a fines de los años 70, en plena dictadura militar y fruto de la instalación del modelo neoliberal a principios de la década de los 80. El Estado deja de participar en la regulación y producción del mercado de trabajo y pasa a ser un Estado subsidiario. Con la privatización de servicios públicos, como educación y salud, desaparecen los subsidios que permitían que las mujeres se mantuvieran en ese espacio junto a los bajos sueldos obtenidos por el jefe de hogar, y la escasa protección social de sus trabajos no alcanzaba para la mantención familiar, condicionando la salida de las mujeres al mundo laboral (Olavarría, 2013). 
Este tipo de organización ha perdido presencia durante los últimos 30 años. Según datos de la Casen, en los inicios de los 90 más de dos tercios de las familias eran nucleares conyugales; en los años 2009-2011 no llegaban al 50\%. Este tipo de organización está desapareciendo debido principalmente a las malas condiciones de trabajo actuales, caracterizadas por la inestabilidad laboral, bajos salarios, inseguridad, miedo e indefensión, lo que afecta la vida en común y la construcción de familia (Olavarría, 2013), dando paso a otras estructuras familiares, como la familia monoparental y/o el regreso de la familia extendida.

\section{¿Quiénes integran el grupo familiar?}

El significado de familia para los jóvenes padres del mundo popular está asociado a la estructura de parentesco de familia extensa o extendida. Esto se debe, probablemente, como señala Jelin (1994), al hecho que en los sectores empobrecidos las redes de parentesco son más confiables que los mecanismos formales, representan apoyo mutuo, operando como recurso para la solución de los problemas de la cotidianidad cuando no se tiene acceso a vías alternativas, cuando estas fallan o fracasan. De ahí su renovado vigor en situaciones de crisis recesivas y en momentos de achicamiento de los servicios del Estado; incluso ayudan a resolver problemas más complejos, como la falta de una política habitacional que entregue mejores oportunidades de participación en materia habitacional a los sectores empobrecidos. Ante ese escenario, la familia de origen se transforma en un salvavidas para la construcción y el proyecto de familia de los jóvenes padres. Los padres de los sujetos de la investigación pueden otorgar esta posibilidad de acogida a sus descendientes debido a que ellos cuentan con su casa propia, obtenida a través de tomas de terreno y/u operaciones sitio (década de los 50, 60 y principios de los 70). Por una parte, en esta fase, el Estado de Bienestar estableció políticas habitacionales que apuntaron a este propósito, y, por otra, relacionada con la anterior, las personas se sentían dueñas de sus vidas, sujetos históricos, capaces de transformar sus propias realidades, y no meros receptores 
de subsidios, sin la mínima incidencia en la mejora de sus condiciones de vida.

Hoy viven en calidad de allegados a sus familias de origen o a las de sus parejas, iniciando su proyecto de vida familiar con la llegada del primer hijo como un hito importante en sus vidas. Ello evidencia un cambio en las estructuras de parentesco, que se origina en la nueva posición de niños y niñas como sujetos de derecho, y a la ley de divorcio, que pone fin a la relación conyugal. En la actualidad, lo indefinido, el "para siempre" ya no son las uniones conyugales o de pareja, el matrimonio. Lo que permanece para toda la vida son los vínculos filiales y así lo sienten los padres jóvenes de La Pincoya. Hijos e hijas construyen familia y se forma parejas.

\section{Los significados de la sexualidad: de la procreación al erotismo}

Las transformaciones económicas y sociales ocurridas durante los últimos años han afectado los significados de la sexualidad y la afectividad y, con ello, las relaciones de pareja. El derecho a tener una vida sexual placentera, a disfrutar la cara erótica de la sexualidad se ha ido apropiando de las mujeres, mitigando su función exclusivamente reproductiva. Desde la lógica patriarcal, el deseo, el placer, propio de la sexualidad erótica, está asociado a la naturaleza masculina; en cambio la sexualidad de las mujeres se vincula exclusivamente a la sexualidad procreadora, reprimiendo una sexualidad experimentada desde el erotismo.

Los padres jóvenes naturalizan su sexualidad entendida como incontinencia sexual, donde el placer de vivir una sexualidad plena queda bajo la responsabilidad de las mujeres. En primera instancia de sus parejas, y si las expectativas no se cumplen, existe la posibilidad de encontrar satisfacción sexual en otras mujeres, justificando la infidelidad en sus relaciones sexo-afectivas.

Uno de los factores que complejiza experimentar y vivir la sexualidad, se relaciona con las condiciones habitacionales. El hacinamiento no ayuda en esta tarea, más bien dificulta los espacios de 
encuentro e intimidad. En ocasiones comparten sus dormitorios con sus hijos, lo que entorpece vivir su sexualidad espontáneamente, debiendo planificar sus encuentros fuera del domicilio. La vida en común de pareja significa hacer frente a la adversidad, y, tras esfuerzo y colaboración, conseguir mejores condiciones de vida para sus familias. Proyectan que el amor que sienten perdure por siempre, fundado en el amor romántico, que "todo lo puede y lo aguanta”. Reconocen, además, que les cuesta expresar sus emociones, reprimen ciertas expresiones que debiliten la imagen de "hombre" desde la lógica patriarcal.

\section{Del hombre al padre: nuevas expresiones, diferentes significados}

Norma Fuller (2000) señala que los significados acerca de paternidad son múltiples, variados y muchas veces contradictorios. En su libro Paternidades en América Latina indica que existen dos grandes perspectivas que han abordado el tema de la paternidad. Una de ellas se asocia a la vertiente psicológica y la otra aborda la paternidad desde una visión sociocultural, resultado de las relaciones sociales en un momento y en un espacio determinados, como construcción cultural, al igual que lo muestra la presente investigación.

Desde una mirada antropológica, en Latinoamérica, la literatura especializada ha enfatizado el desarrollado de la masculinidad desde el machismo. Una de sus representantes, Sonia Montecino, indica que lo masculino se define como el guerrero, el seductor, pero no el padre. La paternidad se representa a través del desinterés del padre respecto de los hijos y es entendida básicamente desde la procreación como prueba de virilidad y hombría, lo que proporciona un modelo de identificación en el que la madre está presente y el padre ausente. El hombre, al carecer de una imagen real, se identificará como hijo, lo que cierra las posibilidades de ser un padre que establece vínculos con sus hijos y sus descendencias. Ello, señala la autora, está relacionado con nuestros orígenes mestizos, el ser engendrado de una madre indígena y un padre español marca un hito importante 
en la conformación de las identidades genéricas latinoamericanas. $\mathrm{Al}$ mezclarse ambas culturas, la indígena y la europea, aparece un nuevo sujeto, híbrido, cuyo nacimiento -real y simbólico- estuvo marcado por la ilegitimidad. La cultura mestiza está sellada por esta "escena original" que se rearticula en el tiempo, entregando sus señales a las actuales identidades de género. El hijo huacho y la madre sola se convierten en un elemento importantísimo en la constitución de la identidad genérica en Chile.

Gabriel Salazar (2012), en cambio, indica que la construcción de las masculinidades y feminidades a lo largo de la historia de Chile está ligada y es influenciada por el sistema social, es decir, por las relaciones e interrelaciones que se establecen con el Estado y el mercado, siendo actores poderosos y relevantes en la construcción de las identidades genéricas, más de lo que se cree. La posición que ocupen estos varones en la estructura social será un elemento condicionante en la expresión de su masculinidad, afectando directamente las prácticas y significados de la paternidad.

La experiencia de padres pertenecientes a sectores empobrecidos está signada por la construcción de las identidades masculinas. Así lo muestra Salazar (2006) en su libro Ser niño huacho en la historia de Chile, en el que analiza específicamente la experiencia de los padres peones, inquilinos y pequeños empresarios, que impulsan a sus hijos (por ausencia o por opción de dignidad) a la calle $\mathrm{y}$,posteriormente, a la generación de una camaradería masculina de "huachos", que constituye el origen histórico de la conciencia proletaria, de la identidad popular. También señala que los huachos no son solo por abandono paterno sino también materno, producto de la estructura social de la época: experiencia paternal de un grupo de varones en particular, que difiere a la experiencia de otros padres posicionados en otro lugar.

\section{¿Qué significa la paternidad en la actualidad?}

La paternidad es un elemento controvertido en la construcción de la identidad masculina en nuestro país. Algunas teorías señalan 
que la paternidad es un vínculo social, que no se determina por la procreación sino por el reconocimiento público. Así, lo hijos no deseados, sea fuera del matrimonio o dentro de una relación estable o de una relación no satisfactoria con la madre, no siempre son aceptados por el padre, la procreación no necesariamente establece un vínculo afectivo y de parentesco con los hijos (Fuller, 2000). Otras, en cambio, señalan que la paternidad se entiende en nuestra cultura desde una dimensión biológica. Rebolledo (1998) cree que la paternidad tiene un valor muy importante en la definición de la hombría, tal vez entendida como el acto de concebir más que la paternidad en sí, que requiere mayor compromiso afectivo y participación durante la crianza de hijos e hijas.

Algunas investigaciones más recientes, señalan que, en la actualidad, la paternidad se ha convertido en un importante canal que tienen los hombres para expresar sus emociones; al igual que antes, la paternidad significa ser responsable económicamente de los hijos, pero además significa cuidado, afectividad, compromiso. Actualmente el vínculo que se establece con los hijos se construye desde la amistad y comunicación más que desde la autoridad. Muchos hombres reconocen que disfrutan el cuidar a sus hijos, convirtiéndose para ellos en un proyecto personal tan importante como el desarrollo profesional. Estos cambios en el ejercicio de la paternidad se entrelazan con los cambios en la identidad masculina (Figueroa-Franzoni, 2011).

La paternidad para los jóvenes padres está relacionada a una dimensión económica, a la responsabilidad de la mantención de sus miembros. La paternidad significa un cambio sustantivo en sus vidas que los hace crecer, madurar, "hacerse hombres" desde la ideología tradicional. Aportar dinero al hogar otorgará una posición social diferente, convirtiendo al hombre en padre, en autoridad para su grupo familiar, clara expresión del patriarcado.

Para los padres de la población La Pincoya la paternidad no está determinada por la procreación, como tampoco por aspectos legales, más bien es el reconocimiento público de ese vínculo a tra- 
vés de la crianza, que les permite enseñar lo que saben, transmitir principios, valores, canalizar sus afectos y emociones. Si bien disfrutan realizarla, entendiéndola como una apuesta al futuro, como una proyección mejorada de los que ellos son, sienten que el medio que los rodea es una amenaza a sus propósitos.

Los padres manifiestan que sus hijos son lo más importante en sus vidas, destacan la relevancia de la cercanía afectiva, de compartir experiencias, lo que conlleva al origen de un vínculo indisoluble.

\section{Reflexiones finales}

Los significados que adquiere la paternidad para los padres jóvenes están cruzados por los significados que adquiere la masculinidad. El escenario económico privilegia la productividad en el trabajo, como eje en la construcción identitaria de los varones: "si eres hombre tienes que trabajar sí o sí”, señala uno de los padres jóvenes entrevistados. De esta manera, se sitúa a los jóvenes padres principalmente como proveedores de la familia y ello incide en la definición de su paternidad. Esta situación se hace difícil cuando los recursos económicos obtenidos por el trabajo no permiten cumplir con lo que se espera, de acuerdo con los mandatos de género impuestos por el patriarcado, reactualizándose la lógica de dominio a través de otros dispositivos que responden a nuevos tiempos.

El sistema económico e ideológico neoliberal imperante exacerba las brechas entre ricos y pobres, en las que el bienestar excesivo de una élite se salda con el trabajo mal remunerado y doméstico de la mayoría de la población chilena, y con un sistema de protección social que, lejos de proteger y resguardar la dignidad de las personas, las impulsa a mostrarse muy carenciados para acceder a los escasos beneficios que el sistema ofrece. Este sistema, a pesar de haberse instalado durante la dictadura militar, en casi 30 años de gobiernos democráticos no ha experimentado cambios profundos que apunten a una mejor redistribución de los recursos. Prueba de lo anterior es la educación. Si consideramos que un mayor nivel 
educacional posibilita mejores opciones laborales, los jóvenes de sectores empobrecidos quedarían excluidos de esta oportunidad de movilidad, no solo por no contar con los recursos financieros que les permitan costear la enseñanza superior, sino también debido a que el sistema educacional los expulsa previamente durante la etapa escolar, generando en ellos desmotivación y afectando su autoestima. La mayoría de los sujetos de la presente investigación no culminaron su enseñanza media, responsabilizándose individualmente de esta situación, lo que invisibiliza las causas estructurales que perpetúan su marginación en el sistema educacional y social, y por lo tanto disminuyen las oportunidades de mejorar sus condiciones de vida.

Los varones jóvenes de la población La Pincoya construyen sus masculinidades a partir de representaciones tradicionales, en un medio que restringe sus posibilidades y les niega las oportunidades para expresar nuevas formas de relacionarse con otros hombres, con las mujeres y consigo mismos. Asimismo, lo hacen identificándose con los valores que configuran lo masculino y que se simbolizan en la heterosexualidad como práctica sexual naturalizada, y con el trabajo, emblema de masculinidad, que les permite participar en el espacio público y satisfacer las exigencias que impone el mercado a través del consumo. También, en la independencia que significa relacionarse con otros varones fuera del control que ofrece el espacio familiar materno.

Estos procesos identitarios se construyen a partir de las diferencias sexuales, que no solo refiere a lo masculino y femenino sino, por sobre todo, a las relaciones entre ambos. Estas relaciones no han experimentado transformaciones profundas en la estructura familiar, puesto que continúan funcionando bajo lógicas jerarquizadas, en las cuales las mujeres no pueden mandar, solo obedecer, autoridad que continua en los varones como expresión de dominación, a pesar la incorporación de éstas al mundo del trabajo, lo que podría haberle otorgado un posicionamiento diferente al obtenido en el ejercicio exclusivo del rol materno. 
Estas pruebas de masculinidad deben ser favorablemente superadas para obtener el prestigio que necesitan para sentirse y verse como hombres, con el consiguiente reconocimiento social de su masculinidad como factor reafirmador. En este esquema, la paternidad no se considera un elemento constitutivo de masculinidad, "ser papá no te influye en ser más o menos hombre". No se requiere ser padre para sentirse hombre. En cambio, creen que la maternidad sí está en directa relación con la identidad femenina, no pudiendo escindir la madre de la mujer. Desde un paradigma tradicional, el modelo mariano se reactualiza, sobrevalorando el rol reproductivo por sobre otros. Se espera que las mujeres prefieran situarse en el espacio familiar para establecer relaciones cercanas con sus hijos, como un espacio natural a su condición de mujer, sin considerar que ello más bien responde a las características del contexto social que las conduce al ámbito de lo reproductivo, principal fuente de obtención de prestigio. La figura del padre está pobremente desarrollada como figura de identificación en algunos sectores sociales, su ausencia histórica tiene causas estructurales que han conducido a su lejanía del espacio familiar, más allá de su voluntad, y que se reproduce de manera inadvertida a través del tiempo.

El sistema social continúa favoreciendo la escasa integración de los varones en el mundo doméstico. Las largas jornadas laborales, los tiempos utilizados en trasladarse, los bajos sueldos, los obligan a invertir tiempo extra en sus trabajos para cumplir con la difícil tarea de mantención de su grupo familiar y de participación en el mercado de consumo como fuente de integración social, en un medio altamente segregador y excluyente; con ello superan la prueba de proveeduría, signo de masculinidad. El hombre debe trabajar sí o sí, de lo contrario pierde su prestigio, se convierte en un ser "inútil", no sirve para los fines que impone el capitalismo a través del patriarcado. Sin embargo, también manifiestan abiertamente disfrutar de la crianza y de la importancia de establecer un fuerte vínculo con sus hijos/as, expresión de modificación en las estructuras de parentesco. Estos jóvenes padres están sometidos a 
la prueba constante de ser buenos como hombres y, simultáneamente, buenos proveedores y padres, preocupados por el bienestar de su familia.

\section{Bibliografía}

Andréu, J. (1998). Las técnicas de análisis de contenido: Una revisión actualizada. España: , Centro de estudios Andaluces.

Badinter, E. (1993). XY La identidad masculina. España: .

Barozet, E., Espinoza, V. y Méndez, M. (2013). Estratificación y movilidad social bajo un modelo neoliberal: El caso de Chile. , 14 (25), 169-191.

Barozet, E. (2012). PPT Características de la desigualdad social en Chile. En: Clase Marginación y Exclusión social. Chile: Universidad de Chile, Magíster Análisis Sistémico de la Sociedad.

Bourdieu, P. (2000). La dominación masculina. Barcelona: Anagrama.

Canales M (2006). La entrevista en profundidad individual. En Canales Cerón, M. (coord.), Metodologías de investigación social (pp. 219-294). Santiago de Chile: LOM.

BANCO MUNDIAL, SERNAM y BID. (2007). Cómo capitalizar el potencial económico de Chile ampliando las opciones laborales de la mujer. Diagnóstico de Género - Chile. Santiago: BM, Sernam y BID.

Duarte, K. (2000). ¿Juventud o juventudes? Acerca de cómo mirar y remirar a las juventudes de nuestro continente. Última década, 8(13), 59-77. Duarte, K. (2011). Privilegios patriarcales en varones jóvenes de sectores empobrecidos ¿cambio o acomodo? Revista de Estudios de Juventud, 95, 45-57.

Duarte, K. (2013). Jóvenes en masculino: entre tradicionales y alternativos. Revista Pasos, DEI. San José de Costa de Rica.

Figueroa, J. G. y Franzoni, J. (2011). Del hombre proveedor al hombre emocional: construyendo nuevos significados de la masculinidad entre varones mexicanos. En Aguayo, F. y Sadler, M. (Editores). Masculinidades y políticas Públicas: Involucrando a hombre en la Equidad de Género (64-82). Santiago: LOM.

Fuller, N. (2000). Significados y prácticas de paternidad entre varones urbanos del Perú. En Fuller, N. (Editora), Paternidades en América Latina (35-90). Lima: Pontificia Universidad Católica del Perú. 
Fuller, N. (2001). Maternidad e identidad femenina, relato de sus desencuentros. En Adolescencia y juventud en América Latina. Costa Rica: LUR.

Giddens, A. (1995). La transformación de la intimidad. Madrid: .

Guba, E. y Lincoln, Y. (2002). Paradigmas en la investigación cualitativa. En Antología de métodos cualitativos en la investigación social. México: Cd.

Jelin, E. (1994). Las familias en América Latina. En Familias siglo XXI. Ediciones de las mujeres $\mathrm{N}^{\circ} 20$, Isis Internacional.

León, M. (1995). La familia nuclear: origen de las identidades hegemónicas femenina y masculina. En Género e identidad: Ensayos sobre los femenino y masculino. Colombia: .

López, R., Figueroa, E. y Gutiérrez P. (2013). La parte del león: Nuevas estimaciones de la participación de los súper ricos en el ingreso de Chile. Santiago de Chile: Universidad de Chile, Facultad de Economía y negocios, .

Montecino, S. (2010). Madres y huachos: alegorías del mestizaje chileno. Santiago de Chile: .

Olavarría, J. (2001). Y todos querían ser (buenos) padres: varones en Santiago de Chile en conflicto. Santiago de Chile: -.

Olavarría, J. (2013). Hombre y familia: conciliación y corresponsabilidad en la medida de los posible. En Seminario Paternidad, Cuidado y Corresponsabilidad. Santiago de Chile: .

Ottone, E. y Vergara, C. (2007). La desigualdad social en América Latina y el caso chileno. Estudios Públicos, 118, 59-91. Redondo, J. (2000). El fracaso escolar y las funciones estructurales de la escuela: Una perspectiva crítica. Revista de Sociología, 14, 7-23.

Rebolledo, L. (1998). Género y espacios de sociabilidad. El barrio, la calle, la casa. Santiago de Chile: Universidad de Chile, Programa interdisciplinario de estudios de género.

Rubin, G. (1996). El tráfico de mujeres: notas sobre la "economía política del sexo”. En Lamas, M. (Compiladora), El género: construcción social de la diferencia sexual. México: .

Salazar, G. (2006). Ser niño huacho en la historia de Chile. Santiago de Chile: .

Salazar, G. (2012). Historia contemporánea de Chile. Volumen IV. Hombría y feminidad. Santiago de Chile: .

Taylor, S. y Bogdan, R. (1987). Introducción a los métodos cualitativos de investigación. Buenos Aires: 
Los significados de la paternidad desde la construcción de lo masculino: el caso de la Pincoya /Jara

Torche, F. (2005). Desigual pero fluido: El patrón chileno de la movilidad en perspectiva comparada. Expansiva, 29.

Valdés, X. (2007). Vida en común. Familia y vida privada en Chile. Santiago de Chile: . 